\title{
Effect of breakfast fat content on glucose tolerance and risk factors of atherosclerosis and thrombosis
}

\author{
David L. Frape ${ }^{1 *}$, Norman R. Williams ${ }^{2}$, Jayshri Rajput-Williams ${ }^{2}$, B. W. Maitland ${ }^{2}$, A. J. Scriven ${ }^{2}$, \\ Christopher R. Palmer ${ }^{3}$ and Reginald J. Fletcher ${ }^{4}$ \\ ${ }^{1}$ N. S. Research, The Priory, Mildenhall, Suffolk IP28 7EE, UK \\ ${ }^{2}$ Pathology Department, Papworth Hospital, Cambridge CB3 8RE, UK \\ ${ }^{3}$ University of Cambridge, Department of Community Medicine, Institute of Public Health, \\ Robinson Way, Cambridge CB2 2SR, UK \\ ${ }^{4}$ The Kellogg Company of Great Britain Ltd., The Kellogg Building, Talbot Road, Manchester M16 OPU, UK
}

(Received 6 November 1997 - Revised 1 May 1998 - Accepted 7 May 1998)

\begin{abstract}
Twenty-four middle-aged healthy men were given a low-fat high-carbohydrate ( $5.5 \mathrm{~g}$ fat; L), or a moderately-fatty, $(25 \cdot 7 \mathrm{~g}$ fat; $\mathrm{M})$ breakfast of similar energy contents for $28 \mathrm{~d}$. Other meals were under less control. An oral glucose tolerance test (OGTT) was given at 09.00 hours on day 1 before treatment allocation and at 13.30 hours on day 29. There were no significant treatment differences in fasting serum values, either on day 1 or at the termination of treatments on day 29. The following was observed on day 29: (1) the M breakfast led to higher OGTT C-peptide responses and higher areas under the curves (AUC) of OGTT serum glucose and insulin responses compared with the OGTT responses to the L breakfast $(P<0.05)$; (2) treatment M failed to prevent OGTT glycosuria, eliminated with treatment L; (3) serum non-esterified fatty acid (NEFA) AUC was $59 \%$ lower with treatment $\mathrm{L}$ than with treatment $\mathrm{M}$, between 09.00 and 13.20 hours $(P<0 \cdot 0001)$, and lower with treatment $\mathrm{L}$ than with treatment $\mathrm{M}$ during the OGTT $(P=0.005)$; (4) serum triacylglycerol (TAG) concentrations were similar for both treatments, especially during the morning, but their origins were different during the afternoon OGTT when the Svedberg flotation unit 20-400 lipid fraction was higher with treatment $L$ than with treatment M $(P=0.016)$; plasma apolipoprotein B-48 level with treatment $\mathrm{M}$ was not significantly greater than that with treatment $\mathrm{L}(P=0 \cdot 086)$; (5) plasma tissue plasminogen-activator activity increased after breakfast with treatment $\mathrm{L}(P=0 \cdot 0008)$, but not with treatment $\mathrm{M}(P=0 \cdot 80)$. Waist:hip circumference was positively correlated with serum insulin and glucose AUC and with fasting LDL-cholesterol. Waist:hip circumference and serum TAG and insulin AUC were correlated with factors of thrombus formation; and the OGTT NEFA and glucose AUC were correlated. A small difference in fat intake at breakfast has a large influence on circulating diurnal NEFA concentration, which it is concluded influences adversely glucose tolerance up to $6 \mathrm{~h}$ later.
\end{abstract}

\section{Dietary fat: Carbohydrate tolerance: Insulin}

High concentrations of circulating non-esterified fatty acids (NEFA) may contribute to the insulin-resistant state (Frayn et al. 1997; Prins, 1997). The concentration of peripheral venous NEFA following a meal reflects leak-back from the action of lipoprotein lipase (EC 3.1.1.34; LPL) and the action of intracellular hormone-sensitive lipase (EC 3.1.1.3; HSL) of adipose tissue (Frayn, 1993). A rise in postprandial blood insulin concentration suppresses the activity of intracellular HSL; but intra-abdominal fat is metabolically very active and has a lower sensitivity than subcutaneous fat to the inhibitory effects of insulin (Bjorntorp, 1990). This is likely to be a cause of the positive association of intraabdominal fat and of waist:hip circumference (W:H) measurements, with risk factors of cardiovascular disease (Williams et al. 1997) and with risk of stroke (Walker et al. 1996). We have previously found (Frape et al. 1997b) that subjects are generally more resistant to insulin at breakfast than at lunch, leading to high circulating levels of insulin

\footnotetext{
Abbreviations: apoB-48, apolipoprotein B-48; AUC, area under the curve; HSL, hormone-sensitive lipase; L, high-carbohydrate low-fat corn flakes breakfast; LPL, lipoprotein lipase; M, moderately-fatty pasty breakfast; ME, metabolizable energy; NEFA, non-esterified fatty acid; OGTT, oral glucose tolerance test; PAI-1, plasminogen-activator inhibitor-1; $S_{f}$, Svedberg flotation unit; TAG, triacylglycerol; t-PA, tissue plasminogen activator; W : H, waist:hip circumference.
}

*Corresponding author: Dr D. L. Frape, fax +44 (0)1638 711120. 
after breakfast; whether this is reflected in the circulating level of NEFA is unclear.

Using healthy middle-aged men, who ranged in $\mathrm{W}: \mathrm{H}$ from 0.80 to $1 \cdot 05$, the purpose of the present study was to determine to what extent small and widely observed isoenergetic differences in breakfast fat and carbohydrate intakes affect glucose tolerance measured several hours later in an oral glucose tolerance test (OGTT). The purpose was also to determine whether these responses were correlated with risk factors of atherosclerosis and thrombosis. The assertion that intolerance would be increased by the fatty breakfast stemmed from the observation previously reported (Frape et al. 1997b) that the glucose response to a fatty lunch was increased by a fatty breakfast. Moreover, the plasma NEFA concentration after this lunch was higher than that for subjects given a carbohydrate breakfast of similar energy content before the fatty lunch (Frape et al. 1997a).

\section{Materials and methods}

Twenty-four healthy, non-smoking Caucasian males, 35-65 years of age, were selected subsequent to medical examination and clinical analysis of blood samples. There were twelve pairs matched according to the characteristic $\mathrm{W}: \mathrm{H} \times$ fasting LDL-cholesterol.

The two dietary treatments were allocated at random within each pair. The treatments were a high-carbohydrate low-fat cereal breakfast (L; composed of $86 \mathrm{~g}$ corn flakes + $300 \mathrm{ml}$ semi-skimmed milk $+250 \mathrm{ml}$ orange juice), or a moderately-fatty breakfast (M; a pasty weighing $86 \mathrm{~g}$, composed of a lean meat-vegetable mixture in a pastry covering, in which the fat was predominately butter; Table 1). The two treatments provided similar amounts of metabolizable energy (ME), and were each taken with one cup of tea or coffee on days 2-28, at home before 09.00 hours, but neither tea nor coffee was given on day 29. All subjects were provided with an evening meal of low-fat cereal that was eaten exclusively at 19.00 hours on days 0

Table 1. Mean composition ( $\mathrm{g}$ ) of a moderately-fatty pasty and a highcarbohydrate low-fat corn flakes meal by chemical analysis*

\begin{tabular}{lcc}
\hline & Cereal† meal & Pasty meal \\
\hline Moisture & $\mathrm{ND}$ & $65 \cdot 1$ \\
Protein (N × 6.25) & $18 \cdot 4$ & $18 \cdot 8$ \\
Fat (Bligh \& Dyer, 1959) & $5 \cdot 5$ & $25 \cdot 7$ \\
Ash & $\mathrm{ND}$ & $3 \cdot 8$ \\
Total carbohydrate & $113 \cdot 0$ & $55 \cdot 9$ \\
Dietary fibre & $0 \cdot 9$ & $3 \cdot 5$ \\
Available carbohydrate & $113 \cdot 0$ & $52 \cdot 3$ \\
Total sugars, as glucose & $46 \cdot 1$ & $4 \cdot 2$ \\
Saturated fatty acids & $3 \cdot 1$ & $14 \cdot 4$ \\
Monounsaturated fatty acids & $1 \cdot 8$ & $9 \cdot 0$ \\
Polyunsaturated fatty acids & $0 \cdot 5$ & $2 \cdot 3$ \\
Energy from carbohydrate (\%) & $78 \cdot 3$ & $40 \cdot 4$ \\
Energy from fat (\%) & $8 \cdot 8$ & $43 \cdot 1$ \\
Metabolizable energy (MJ per meal) & $2 \cdot 31$ & $2 \cdot 17 \ddagger$ \\
& & $2 \cdot 25 \S$ \\
\hline
\end{tabular}

ND, not determined.

* Data refer to all food eaten. Any uneaten food was analysed and subtracted from the total.

$\dagger$ Including $300 \mathrm{ml}$ semi-skimmed milk and $250 \mathrm{ml}$ orange juice.

‡Days 2-28.

$\S$ Test day 29. and 28 and they were then fasted until 09.00 hours on days 1 and 29 . By analysis, treatment $\mathrm{L}$ provided $6.5 \%$ more $\mathrm{ME}$ than $\mathrm{M}$ on days 2-28. On day 29 the difference was lessened to $2.7 \%$ by proportionately increasing treatment $\mathrm{M}$. On days 2-28 some freedom was given in the composition of the two other daily meals taken at mid-day and in the evening. Highfat foods were avoided, fish was excluded, and all meals were taken at home, but recorded in a diary and assessed using data provided by Paul \& Southgate (1978) and Holland et al. $(1988,1989)$, with dietary fibre estimated from their tables by the method of Southgate (Wenlock et al. 1985). These two meals provided an estimated mean of 8.8 MJ ME per subject daily and contained for treatments $L$ and $M$ respectively an estimated mean (g) of: fat 80 and 77, SED 4.3; protein 94 and 101 , SED $10 \cdot 5$; carbohydrate 258 and 256, SED 36.7; dietary fibre 22 and 28 , SED $3 \cdot 8$. None of these differences was significant $(P<0 \cdot 05)$. In the two meals fat provided approximately $33 \%$ of the energy, protein $19 \%$ and carbohydrate $47 \%$. Subjects were prohibited from taking any drug containing salicylic acid, or sodium salicylate, and none smoked or received prescription drug treatment during the course of the study.

On day 1 fasting blood characteristics were measured and all subjects were given an OGTT at 09.00 hours. In our laboratory $75 \mathrm{~g}$ glucose leads to unacceptable glucosuria in middle-aged subjects, causing a systematic error; thus, $66 \mathrm{~g}$ glucose monohydrate ( $60 \mathrm{~g}$ glucose) were given in approximately $400 \mathrm{ml}$ water. On day 29 each subject received their previously allocated L or M breakfast at 09.00 hours, followed at 13.30 hours by an OGTT. Water was available for drinking on both days 1 and 29. Urination did not occur between 0 and 130 min following each glucose dose, and then a urine sample was provided at $130 \mathrm{~min}$ following each dose. All test meals and metabolic measurements were carried out at Papworth Hospital, Cambridge, and were synchronized within each pair on days 1 and 29.

\section{Response measurements}

Body weight, height and the circumference at the waist and hips were recorded 'blind' by the same nurse, when fasting, at the same time of day during medical examination on days 1 and 29 . W: $\mathrm{H}$ values varied from 0.80 to 1.05 and the measurements were made at the levels of the umbilicus and the greater trochanter of the femur. An indwelling antecubital vein cannula was fitted at 08.00 hours on days 1 and 29. Blood samples $(12 \mathrm{ml})$ were taken on each day preOGTT and at 30, 60, 90 and 120 min following the glucose dose on days 1 and 29. On day 29, blood $(12 \mathrm{ml})$ was also taken when fasting and at $60,120,180$ and $260 \mathrm{~min}$ after breakfast. The $260 \mathrm{~min}$ sample served also as the pre-OGTT sample on day 29. All subjects were seated between blood sampling times and during phlebotomy. The cannulas were kept patent by injection of $2 \mathrm{ml}$ physiological saline $(9 \mathrm{~g}$ $\mathrm{NaCl} / \mathrm{l}$ ) after sampling. During phlebotomy the first sample of $2 \mathrm{ml}$ was discarded and subsequent samples were held in Sarstedt Monovette ${ }^{\circledR}$ tubes (Sarstedt, Leicester, UK) of the following types: serum gel for measurement of fasting cholesterol, NEFA, glycerol, glucose, insulin and C-peptide; citrate for haematology and platelet aggregation; Stabilyte ${ }^{\circledR}$ for tissue plasminogen-activator (t-PA) activity 
and plasminogen-activator inhibitor-1 antigen (PAI-1) determination; $\mathrm{K}_{3}$ EDTA for ultracentrifugation, and lithiumheparin for apolipoprotein B-48 (apoB-48) measurement. The citrate tubes were then held at room temperature until required for the analytical procedure. Other serum samples were held at $+4^{\circ}$ and determinants analysed on the day of collection. Where this was not so, samples were held at $+4^{\circ}$ and were analysed within $24 \mathrm{~h}$ of collection, except for insulin, C-peptide, t-PA, PAI-1 and apoB-48 samples, which were held at $-70^{\circ}$ and analysed in a single run at the end of the study. Serum glucose, insulin and C-peptide were determined by the methods described in Frape et al. (1997b). Triacylglycerols (TAG) were measured using a Hitachi 717 instrument (Boehringer Mannheim UK Ltd., Lewes, East Sussex, UK) as the difference between serum total and free glycerol concentrations, using a kit (Sigma Diagnostics, Poole, Dorset, UK), employing a colorimetric reaction before and after enzymic hydrolysis of the TAG. NEFA were measured by means of a colorimetric reaction following the formation of acyl-CoA, using a Hitachi 911 instrument, with a kit (Wako Chemicals $\mathrm{GmbH}$, Neuss, Germany).

Platelet aggregation was measured using ADP and collagen as agonists, having final concentrations of $18 \cdot 2 \mu \mathrm{mol} / \mathrm{l}$ and $0.17 \mathrm{mg} / \mathrm{ml}$ respectively. Maximum aggregation and its maximum rate were assessed within $5 \mathrm{~min}$ of the agonist addition in a platelet aggregometer (Bio-Data PAP-4C; Alpha Laboratories, Eastleigh, Hants., UK), using plateletrich plasma. t-PA activity, measured in the first six pairs of subjects, and PAI-1 antigen were assessed using commercial kits (Catalogue nos. 1103 and 210221; Biopool, Umea, Sweden). ApoB-48 in plasma was determined using a specific ELISA (Lovegrove et al. 1996) by Dr B. J. Gould, School of Biological Sciences, University of Surrey, Guildford, Surrey GU2 5XH, UK. VLDL-TAG and remnant TAG were determined by analysis of the glycerol content of the Svedberg flotation unit $S_{f}, 20-400$ lipid fraction after density-gradient ultracentrifugation (Terpstra, 1985). Serum LDL-cholesterol was estimated using the method of Friedewald et al. (1972). Urine samples taken at $130 \mathrm{~min}$ following glucose consumption on days 1 and 29 were assessed 'blind' for glucose, using N-Multistix ${ }^{\circledR}$ SG (Bayer Diagnostics plc, Evans House, Basingstoke, Hants., UK). The intra-assay CV for the determinations were respectively $(\%)$ : glucose $1 \cdot 3$, total glycerol $0 \cdot 9$, free glycerol 3.6, TAG 3.7, NEFA 2.2, $S_{f}$ 20-400-TAG 11.4, apoB-48 $3 \cdot 8$, t-PA $7 \cdot 9$, PAI-1 $4 \cdot 9$. The intra-assay CV for platelet aggregation varied from 1.7 to $8.3 \%$ for the various measurements. For maximum aggregation with ADP and collagen intra-assay $\mathrm{CV}$ were 3.4 and $2.1 \%$ respectively and for collagen lag time $8.3 \%$. The inter-assay CV for the $\mathrm{W}: \mathrm{H}$ measurement was $1.72 \%$. The tendency of platelets to disaggregate once aggregated over a $5 \mathrm{~min}$ period under the influence of ADP was scored 'blind'. The range of scoring was +3 to -5 ; platelets continuing to aggregate strongly were scored +3 and those disaggregating rapidly were scored -5 .

\section{Statistical methods}

Responses for all repeated measurement variables were summarized at individual subject level by area under the curve (AUC; Altman, 1991), calculated by applying the trapezium rule for the OGTT response on days 1 and 29 and for the period 09.00-13.20 hours on day 29. The baseline for AUC was zero. Where the times of blood sampling deviated by more than $0.5 \mathrm{~min}$ from the nominal time, the actual time was used in the trapezium calculations. Treatment comparisons were also made between zero-time and 60 min post glucose dose (peak serum glucose) and between treatments at 12.00 hours, when the serum NEFA differences were expected, from evidence in previous studies (Frape et al. 1997a), to be maximum. Variables not normally distributed were log-transformed towards normality. The results were compared by $t$ test, and SEM and CI indicate the variation within treatment. The level of significance selected for treatment differences between single time-point mean values in Figs. $1-6$ was $P<0 \cdot 05$.

The Pearson correlation coefficient was employed to assess associations. All comparisons were carried out with SPSS for Windows (Statistical Package for the Social Science, 1993) and where appropriate by Microsoft Excel version 5.0a for Windows software (Microsoft Corporation, Seattle, WA, USA).

\section{Ethical considerations}

The protocol for the experiment was approved by the Huntingdon Area Medical Ethics Committee and all subjects gave informed written consent to participate.

\section{Results}

There was no significant difference between treatments for fasting blood characteristics on either day 1 or day 29, or for the AUC values of glucose, insulin, TAG or NEFA on day 1 (Table 2). The natural logarithm of fasting and OGTT values for insulin, and OGTT values for C-peptide, were used in the analysis.

\section{Insulin}

Treatment L led to a smaller OGTT insulin $\ln$ AUC $(P=0.038)$ compared with treatment $\mathrm{M}$ on day 29 (Fig. 1), and it caused a smaller increase within subject from day 1 to day 29 in insulin $\ln$ AUC than the increase within subject resulting from treatment $\mathrm{M}(P=0 \cdot 0036$; Table 3$)$.

\section{Glucose}

Three subjects in each treatment group demonstrated glycosuria during the OGTT on day 1 . On day 29, the same three in treatment $\mathrm{M}$ continued to excrete glucose, but none of those in treatment $\mathrm{L}$ did so. Treatment $\mathrm{L}$ led to a smaller OGTT glucose AUC on day 29 compared with treatment M $(P=0.0056$; Fig. 2), and it caused a decrease within subject from day 1 to day 29 in glucose AUC compared with an increase for treatment $\mathrm{M}(P=0 \cdot 0057$; Table 3). Day 1 OGTT glucose AUC was correlated with day 1 OGTT NEFA AUC $(r 0 \cdot 52, P=0 \cdot 0098)$.

\section{C-peptide}

C-peptide was measured during the OGTT on day 29 only and the results for eleven pairs of subjects are given, as one 
Table 2. Serum fasting values for insulin ( $\mathrm{mU} / \mathrm{l}$ ), glucose, triacylglycerol (TAG), non-esterified fatty acids (NEFA), and total and LDL-cholesterol (mmol/l) before (day 1 ) and after $28 \mathrm{~d}$ (day 29) of receiving a high-carbohydrate low-fat corn flakes breakfast (L) or a moderately-fatty pasty breakfast (M) and areas under the curves (AUC) of serum values (mmol/l.min) on day 1 during a morning oral glucose tolerance test (OGTT) before allocation to treatment of healthy middle-aged men*

(Values are means with their standard errors for twelve subjects, except for non-normally distributed fasting insulin where values are medians and interquartile ranges (IQR))

\begin{tabular}{|c|c|c|c|c|c|c|c|c|}
\hline & \multicolumn{4}{|c|}{ Day 1 pretreatment } & \multicolumn{4}{|c|}{ Day 29} \\
\hline & \multicolumn{2}{|c|}{$\mathrm{L}$} & \multicolumn{2}{|c|}{$\mathrm{M}$} & \multicolumn{2}{|c|}{$\mathrm{L}$} & \multicolumn{2}{|c|}{ M } \\
\hline & $\begin{array}{c}\text { Mean } \\
\text { (Median) }\end{array}$ & $\begin{array}{c}\mathrm{SE} \\
(\mathrm{IQR})\end{array}$ & $\begin{array}{c}\text { Mean } \\
\text { (Median) }\end{array}$ & $\begin{array}{c}\mathrm{SE} \\
(\mathrm{IQR})\end{array}$ & $\begin{array}{c}\text { Mean } \\
\text { (Median) }\end{array}$ & $\begin{array}{c}\mathrm{SE} \\
(\mathrm{IQR})\end{array}$ & $\begin{array}{c}\text { Mean } \\
\text { (Median) }\end{array}$ & $\begin{array}{c}\mathrm{SE} \\
(\mathrm{IQR})\end{array}$ \\
\hline \multicolumn{9}{|l|}{ Fasting values } \\
\hline Insulin (In) & 6.55 & $6 \cdot 43$ & 8.65 & $3 \cdot 78$ & $8 \cdot 30$ & 6.98 & 8.65 & 3.98 \\
\hline Glucose & $5 \cdot 10$ & 0.17 & 4.98 & $0 \cdot 12$ & $5 \cdot 19$ & $0 \cdot 17$ & $5 \cdot 10$ & 0.11 \\
\hline Total cholesterol & $5 \cdot 69$ & 0.41 & $5 \cdot 85$ & 0.31 & $5 \cdot 43$ & 0.38 & 5.90 & 0.32 \\
\hline LDL-cholesterol & $3 \cdot 83$ & 0.34 & 3.97 & 0.23 & 3.64 & 0.31 & 4.03 & 0.25 \\
\hline \multicolumn{9}{|l|}{ OGTT AUC } \\
\hline Insulin (In; mU/I.min) & $390 \cdot 2$ & $20 \cdot 5$ & $390 \cdot 1$ & $16 \cdot 5$ & & & & \\
\hline Glucose & $824 \cdot 8$ & 56.5 & $739 \cdot 3$ & $28 \cdot 6$ & & & & \\
\hline TAG & $158 \cdot 2$ & $38 \cdot 2$ & $160 \cdot 1$ & 24.9 & & & & \\
\hline
\end{tabular}

${ }^{*}$ For details of subjects and procedures, see pp. 324-325 and for details of composition of breakfast meals, see Table 1.

pair exhibited outlier responses. The treatment comparison indicated that treatment $\mathrm{L}$ was associated with a smaller mean increment in serum ln C-peptide concentration over the $2 \mathrm{~h}$ of the OGTT than that in treatment M (L, 4.76 (SEM $0.02) v . \mathrm{M}, 4 \cdot 85$ (SEM 0.02) $\mu \mathrm{g} / \mathrm{l}, P=0 \cdot 026$; Fig. 3).

\section{Triacylglyerols, non-esterified fatty acids, free glycerol and lipoproteins}

On day 29 the OGTT TAG AUC was not significantly larger for the $\mathrm{L}$ group than for the $\mathrm{M}$ group $(P=0 \cdot 74$; Table 4 and Fig. 4). The origin of the TAG was apparently different

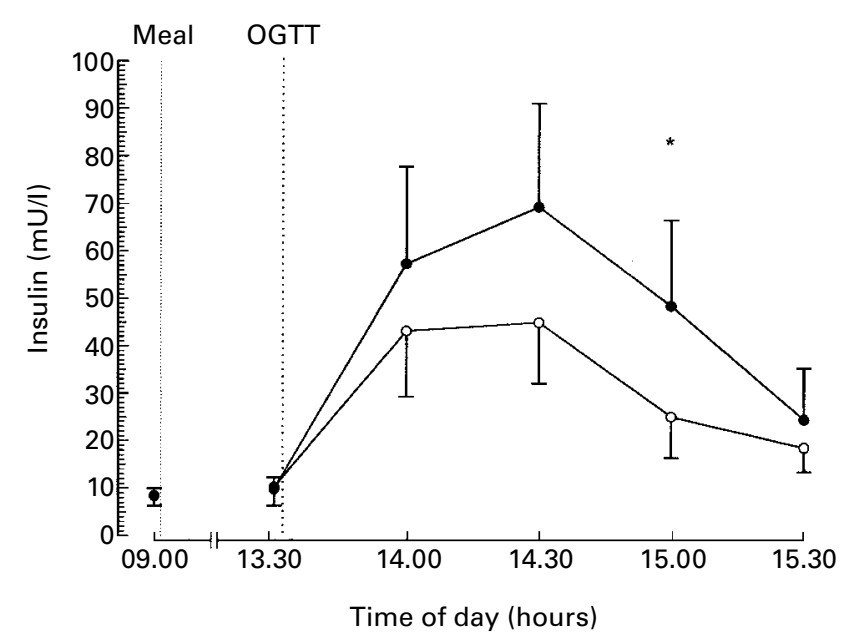

Fig. 1. Serum In insulin concentrations ( $\mathrm{mU} / \mathrm{l})$ for twelve healthy middleaged men after $28 \mathrm{~d}$ of receiving a high-carbohydrate low-fat corn flakes breakfast $(\bigcirc)$ or a moderately-fatty pasty breakfast $(\mathbf{\bullet})$, during an oral glucose tolerance test (OGTT) in the afternoon after a breakfast meal at 09.00 hours. Points are arithmetic means with $\mathrm{Cl}$ represented by vertical bars. Mean value was significantly different from that for lowfat breakfast: ${ }^{*} P<0.05$. For details of subjects and procedures, see pp. 324-325 and for details of breakfast meals, see Table 1. between treatments during the OGTT. At this time the serum TAG for treatment $\mathrm{L}$ compared with $\mathrm{M}$ was derived to a greater extent from the lipoprotein fraction $S_{f} 20-400$ $(P=0 \cdot 016$; Table 5$)$ and TAG derived from the fraction $S_{f}$ $>400$ was scant in both groups. The difference between treatments in plasma apoB-48 concentration during the period 13.20-15.00 hours was not significant $(P=0.086$; Table 5).

NEFA AUC during the OGTT was considerably lower for the $\mathrm{L}$ group than for the $\mathrm{M}$ group $(P=0 \cdot 0001)$. The NEFA values were also lower at the start of the OGTT (13.30 hours) and at each collection time until 15.00 hours for treatment $\mathrm{L}$ than those for treatment $\mathrm{M}(P=0 \cdot 0048)$. NEFA

Table 3. Areas under the curves (AUC) of serum glucose and insulin responses to treatment during the oral glucose tolerance test (OGTT) between 13.30 and 15.30 hours on day 29, and the mean within subject change in AUC response from day 1 to day 29 during the OGTT for healthy middle-aged men receiving a high-carbohydrate low-fat corn flakes breakfast (L) or a moderately-fatty pasty breakfast (M) for $28 \mathrm{~d}^{*}$

(Values are means with their standard errors for twelve subjects)

\begin{tabular}{lcc}
\hline & $\begin{array}{c}\text { Glucose } \\
\text { (mmol/l.min) }\end{array}$ & $\begin{array}{c}\text { Insulin } \\
\text { In(mU/l.min) }\end{array}$ \\
\hline Day 29 & $797 \cdot 2$ & $402 \cdot 0$ \\
Treatment L Mean & $34 \cdot 6$ & $20 \cdot 8$ \\
$\quad$ SEM & $970 \cdot 0$ & $449 \cdot 3$ \\
Treatment M Mean & $56 \cdot 4$ & $13 \cdot 4$ \\
$\quad$ SEM & $0 \cdot 0056$ & 0.038 \\
Statistical significance of difference: $P$ & & \\
Days (1-29) & $-27 \cdot 6$ & $11 \cdot 8$ \\
Treatment L Mean & $52 \cdot 7$ & 11.0 \\
& $230 \cdot 6$ & $59 \cdot 2$ \\
Treatment M Mean & $57 \cdot 6$ & $12 \cdot 4$ \\
SEM & 0.0057 & 0.0036 \\
Statistical significance of difference: $P$ & &
\end{tabular}

* For details of subjects and procedures, see pp. 324-325 and for details of composition of breakfast meals, see Table 1 . 


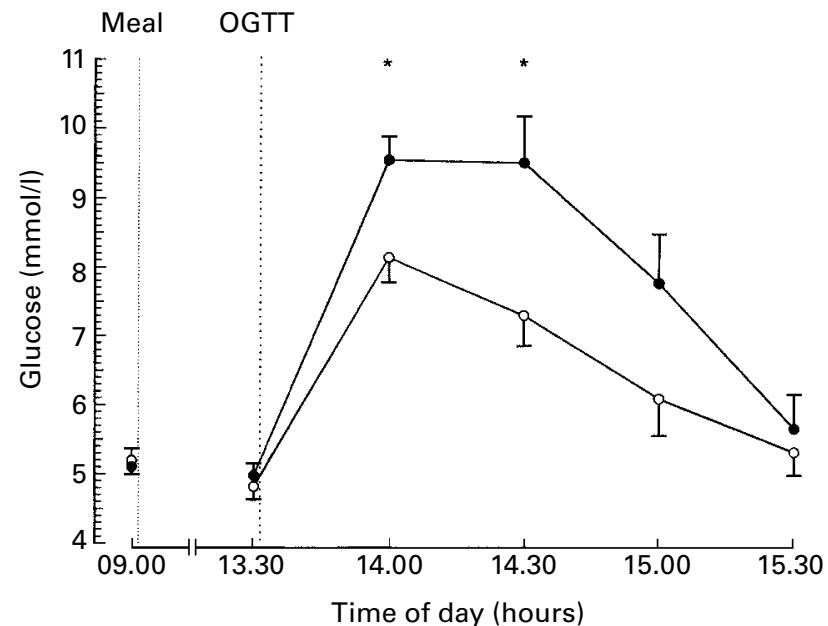

Fig. 2. Serum glucose concentrations $(\mathrm{mmol} / \mathrm{l})$ for twelve healthy middle-aged men after $28 \mathrm{~d}$ of receiving a high-carbohydrate low-fat corn flakes breakfast $(O)$ or a moderately-fatty pasty breakfast $(\bullet)$, during an oral glucose tolerance test (OGTT) in the afternoon after a breakfast meal at 09.00 hours. Points are means with their standard errors represented by vertical bars. Mean values were significantly different from those for the low-fat breakfast; ${ }^{*} P<0.05$. For details of subjects and procedures, see pp. 324-325 and for details of breakfast meals, see Table 1.

values at $60 \mathrm{~min}$ post-OGTT were lower than those pre-OGTT in both groups $(P=0.0001)$; the decline in NEFA concentration did not commence until $30 \mathrm{~min}$ post-OGTT (Fig. 5). The OGTT free glycerol AUC values for the two treatments were not significantly different $(P=0 \cdot 39$; Fig. 6).

The difference between treatments for serum NEFA reached a maximum at 12.00 hours on day 29 , before the OGTT, when serum free glycerol and NEFA were greater for the $\mathrm{M}$ group than for the $\mathrm{L}$ group $(P=0.0008$ and $P<0.0001$ respectively; Figs. 5 and 6).

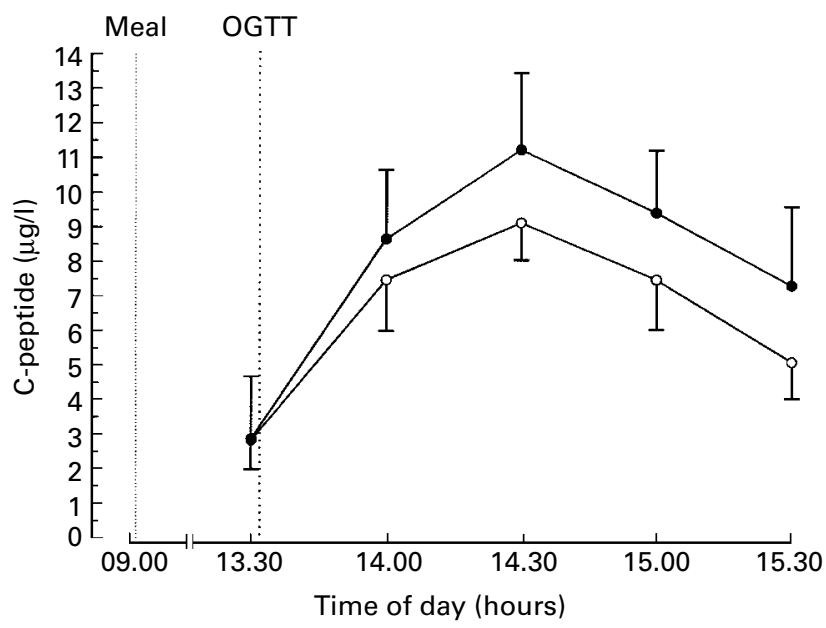

Fig. 3. Serum In C-peptide concentrations $(\mu \mathrm{g} / \mathrm{l})$ for eleven healthy middle-aged men after $28 \mathrm{~d}$ of receiving a high-carbohydrate low-fat corn flakes breakfast $(O)$ or a moderately-fatty pasty breakfast $(\bullet)$, during an afternoon oral glucose tolerance test (OGTT). A breakfast was given at 09.00 hours. One pair of subjects of the twelve pairs was excluded on the grounds of extended responses following breakfast meal on day 29. Points are arithmetic means with $\mathrm{Cl}$ represented by vertical bars. For details of subjects and procedures, see pp. 324325 and for details of breakfast meals, see Table 1.

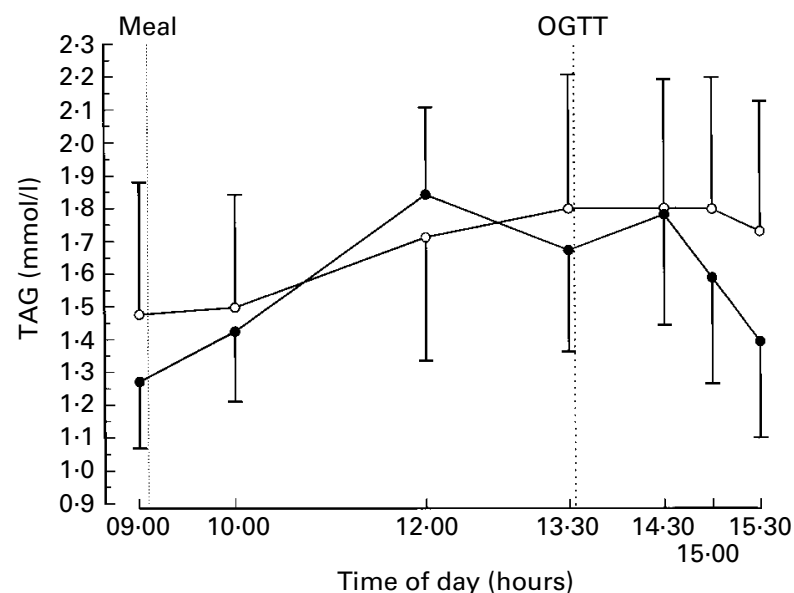

Fig. 4. Serum triacylglycerol (TAG) concentrations ( $\mathrm{mmol} / \mathrm{l})$ for twelve healthy middle-aged men after $28 \mathrm{~d}$ of receiving a high-carbohydrate low-fat corn flakes breakfast $(O)$ or a moderately-fatty pasty breakfast (๑). After a breakfast meal at 09.00 hours serum TAG were measured during the morning and again over $120 \mathrm{~min}$ of an oral glucose tolerance test (OGTT) in the afternoon. Points are means with their standard errors represented by vertical bars. For details of subjects and procedures, see pp. 324-325 and for details of breakfast meals, see Table 1.

After breakfast in the morning on day 29 (09.00-13.20 hours) NEFA AUC for treatment L was only $59 \%$ of that for treatment $\mathrm{M}$ (Fig. 5; $P<0 \cdot 0001$ ). The free glycerol AUC responses were also different $(P=0 \cdot 049 ;$ Fig. 6). On the other hand, serum TAG AUC values during this interval were very similar for the two treatments $(P=1 \cdot 00$; Table 4 and Fig. 4).

\section{Physical characteristics}

There was no significant difference between treatments in physical characteristics on day 1 , or in body weight and BMI changes during the experiment. However, treatment M

Table 4. Areas under the curves (AUC) of serum triacylglycerol (TAG) and non-esterified fatty acid (NEFA) responses to treatment after breakfast on day 29 (09.00-13.20 hours) and during the oral glucose tolerance test (OGTT; $13.30-15.30$ hours) on day 29 for healthy middle-aged men receiving a high-carbohydrate low-fat corn flakes breakfast (L) or a moderately-fatty pasty breakfast (M) for $28 \mathrm{~d}^{*}$ (Values are means with their standard errors for twelve subjects)

\begin{tabular}{|c|c|c|}
\hline & $\begin{array}{c}\text { TAG } \\
\text { (mmol//.min) }\end{array}$ & $\begin{array}{c}\text { NEFA } \\
(\mathrm{mmol} / \mathrm{l} \cdot \mathrm{min})\end{array}$ \\
\hline \multicolumn{3}{|l|}{ 09.00-13.20 hours } \\
\hline Treatment $L$ Mean & 440 & $60 \cdot 9$ \\
\hline SEM & 101 & $4 \cdot 2$ \\
\hline Treatment M Mean & 435 & $103 \cdot 5$ \\
\hline SEM & 66 & $5 \cdot 8$ \\
\hline Statistical significance of difference: $P$ & $1 \cdot 0$ & $<0.0001$ \\
\hline \multicolumn{3}{|l|}{$13.30-15.30$ hours } \\
\hline Treatment L Mean & 215 & $24 \cdot 6$ \\
\hline SEM & 48 & 1.97 \\
\hline Treatment M Mean & 199 & $43 \cdot 0$ \\
\hline SEM & 38 & $2 \cdot 64$ \\
\hline Statistical significance of difference: $P$ & 0.74 & $<0.0001$ \\
\hline
\end{tabular}

* For details of subjects and procedures, see pp. 324-325 and for details of composition of breakfast meals, see Table 1. 
Table 5. Mean plasma Svedberg flotation unit $\left(S_{f}\right) 20-400$ triacylglycerol (TAG; mmol/l) and apolipoprotein B-48 (apoB-48; mg/l) preglucose dose (13.20 hours) and during the glucose tolerance test on day 29 for healthy middle-aged men receiving a high-carbohydrate low-fat corn flakes breakfast (L) or a moderately-fatty pasty breakfast (M) for $28 d^{*}$

(Mean values with their standard errors for twelve subjects)

\begin{tabular}{lcccccc}
\hline & & \multicolumn{2}{c}{$\begin{array}{c}S_{f} 20-400 \\
\text { TAG }\end{array}$} & & \multicolumn{2}{c}{ ApoB-48† } \\
$\begin{array}{l}\text { Time of day } \\
\text { (hours) }\end{array}$ & Treatment & Mean & SEM & & Mean & SEM \\
\hline 13.20 & $\mathrm{~L}$ & 0.99 & 0.19 & & 2.04 & 0.10 \\
& $\mathrm{M}$ & 0.57 & 0.23 & & 2.52 & 0.29 \\
14.30 & $\mathrm{~L}$ & 1.02 & 0.22 & & 1.88 & 0.08 \\
& $\mathrm{M}$ & 0.60 & 0.25 & & 2.45 & 0.26 \\
15.00 & $\mathrm{~L}$ & 0.95 & 0.20 & & \\
& $\mathrm{M}$ & 0.63 & 0.31 & & \\
15.30 & $\mathrm{~L}$ & 0.95 & 0.21 & & \\
& $\mathrm{M}$ & 0.54 & 0.26 & & \\
\hline
\end{tabular}

${ }^{*}$ For details of subjects and procedures, see pp. 324-325 and for details of breakfast meals, see Table 1.

†ApoB-48 sample at 14.30 hours pooled with the sample at 15.00 hours.

increased the $\mathrm{W}: \mathrm{H}$ measurement $(0 \cdot 016$ (SD 0.028)); compared with a loss amongst the treatment $\mathrm{L}$ group $(-0 \cdot 015$ (SD 0.038 ); treatment difference, $P=0.035$ ). This was accounted for mainly by a change in waist measurement $(P=0.063)$. However, there was an opposing change in hip measurement $(P=0.37)$, and so the apparent treatment difference in $\mathrm{W}: \mathrm{H}$ may have been chance. In order to exclude any spurious influences or treatment effects, the correlations of metabolic variables with the $\mathrm{W}: \mathrm{H}$ are based on the $\mathrm{W}: \mathrm{H}$ values for day 1 only.

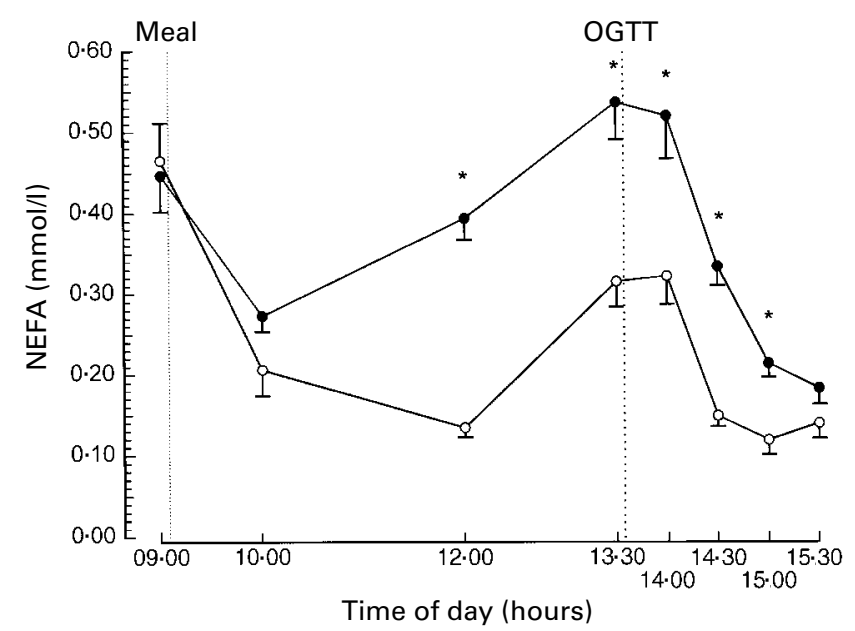

Fig. 5. Serum non-esterified fatty acid (NEFA) concentrations ( $\mathrm{mmol} / \mathrm{l})$ for twelve healthy middle-aged men after $28 \mathrm{~d}$ of receiving a highcarbohydrate low-fat corn flakes breakfast $(O)$ or a moderately-fatty pasty breakfast (๑). After a breakfast meal at 09.00 hours serum NEFA were measured during the morning and again over $120 \mathrm{~min}$ of an oral glucose tolerance test (OGTT) in the afternoon. Points are means with their standard errors represented by vertical bars. Mean values are significantly different from those for the low-fat breakfast: $P<0.05$. For details of subjects and procedures, see pp. 324-325 and for details of breakfast meal, see Table 1.

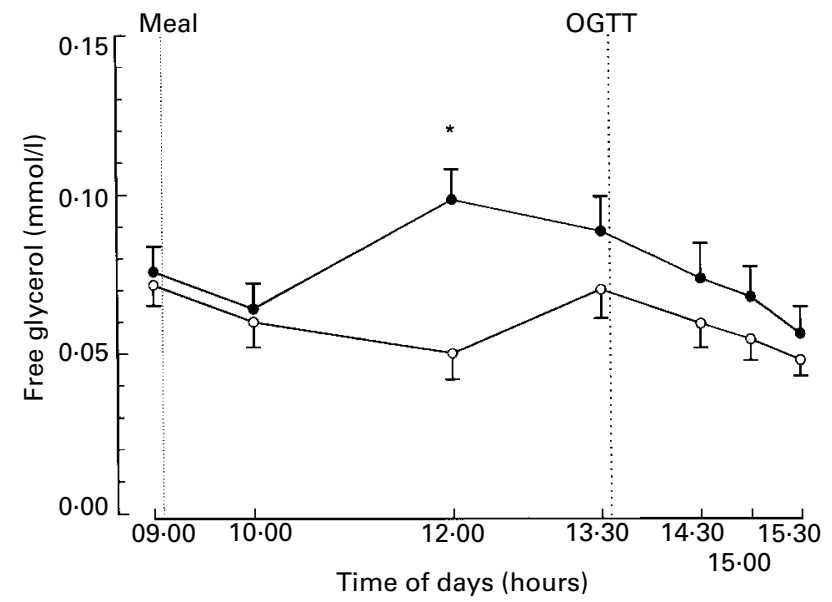

Fig. 6. Serum free glycerol concentrations ( $\mathrm{mmol} / \mathrm{l})$ for twelve healthy middle-aged men after $28 \mathrm{~d}$ of receiving a high-carbohydrate low-fat corn flakes breakfast $(O)$ or a moderately-fatty pasty breakfast $(\bullet)$. After a breakfast meal at 09.00 hours serum glycerol was measured during the morning and again over $120 \mathrm{~min}$ of an oral glucose tolerance test (OGTT) in the afternoon. Points are means with their standard errors represented by vertical bars. Mean value was significantly different from that for low-fat breakfast: ${ }^{*} P<0.05$. For details of subjects and procedures, see pp. 324-325 and for details of breakfast meal, see Table 1.

\section{Metabolic factors of thrombus formation and atherosclerosis}

There was no significant treatment difference for platelet aggregation, or for PAI-1 antigen, on day 29. On day 29 plasma t-PA showed a linear diurnal increase during the period 09.00-13.20 hours with treatment $\mathrm{L}(P=0.0008)$, whereas no significant increase occurred with treatment $\mathrm{M}$ $(P=0 \cdot 8)$. The fatty meal was associated with a decrease in plasma t-PA activity during the first postprandial hour. Correlations were detected in the measurements on day 1 for several risk factors. The values indicate an association between $\mathrm{W}: \mathrm{H}$ and serum glucose AUC $(r 0 \cdot 49, P=0 \cdot 016)$, insulin AUC $(r 0.42, P=0.042)$, fasting t-PA activity $(r-0.63, P=0.028)$ and fasting LDL-cholesterol $(r 0.49$, $P=0 \cdot 015)$. Serum insulin AUC was correlated with plasma PAI-1 antigen $(r 0 \cdot 74, P<0 \cdot 0001)$. For the values on days 1 and 29 combined within subject, where there was no significant treatment effect, serum TAG AUC was correlated with fasting platelet aggregation lag time (agonist collagen; $r-0.42, P=0.043)$ and with fasting platelet maximum aggregation (agonist collagen; $r$ 0.62, $P=$ 0.0013). Fasting LDL-cholesterol was also correlated with fasting platelet aggregation lag time (agonist collagen; $r-0.52, P=0.0089$ ). The tendency of platelets to disaggregate under the influence of ADP, an effect previously found to be correlated with risk of heart disease (Elwood et al. 1991), was not significantly correlated with $\mathrm{W}: \mathrm{H}$ $(r-0 \cdot 35, P=0 \cdot 06)$.

\section{Discussion}

\section{Glucose tolerance}

Decreased insulin sensitivity and elevated fasting serum insulin and glucose concentrations are related to risk factors 
of heart disease (Ohlson et al. 1989). In the present study treatment $\mathrm{M}$ led to higher glucose, insulin and C-peptide responses $(P<0.05)$ during the OGTT on day 29. The changes in glucose tolerance and insulin response from day 1 to day 29 were also significantly different between treatments. Such differences over time could have resulted from conducting the measurements in the morning of day 1 and the afternoon of day 29. However, the differences were in full accord with our previous observations that whereas carbohydrate meals given in the morning and afternoon yielded similar glucose AUC responses (morning 26.3 (SE 1.3) $v$. afternoon 26.6 (SE 0.82) mmol/l.h; $P=0.8$ ), fatty meals of similar energy content yielded different glucose AUC responses (morning 22.2 (SE 0.6) $v$. afternoon 23.9 (SE 0.5) $\mathrm{mmol} / \mathrm{l} . \mathrm{h} ; P=0.004$ ) and subjects given the fatty lunch following the fatty breakfast yielded larger glucose AUC reponses than did those given the fatty lunch following the carbohydrate breakfast (respectively morning 23.9 (SE 0.5) $v$. afternoon 22.4 (SE 0.4), mmol/ litre.h; $P=0 \cdot 03$; Frape et al. 1997b). Thus, small differences in fat intake at breakfast can influence glucose tolerance several hours later. In the present study, serum insulin AUC was also highly correlated with plasma PAI-1 antigen levels, consistent with observations by Lopez-Segura et al. (1996) and Toft et al. (1997) in men, and reinforcing a possible link of insulin function with risk factors of thromboembolic disease.

\section{Origin of postprandial triacylglycerol}

Lui et al. (1983) reported that the daily intake by healthy subjects of large amounts of carbohydrate containing 220$250 \mathrm{~g}$ sucrose $/ \mathrm{kg}$, stimulated TAG synthesis and release as endogenous apoB-100 VLDL-TAG in the fasting state. In our study, treatment $\mathrm{M}$ provided $20 \mathrm{~g}$ more fat and $57 \mathrm{~g}$ less carbohydrate than treatment $\mathrm{L}$ at breakfast, yet the postprandial serum TAG concentration was similar for the two treatments. The provision of natural sucrose $(12 \mathrm{~g}$ fructose residue; in orange juice with the carbohydrate meal) may have contributed to this similarity. The higher afternoon OGTT plasma $S_{f}$ 20-400-TAG concentration with treatment $\mathrm{L}(P=0.016)$ probably reflected the effect of dietary carbohydrate on the plasma VLDL response (Jeppesen et al. 1995).

\section{Waist:hip circumference and its relation to other risk factors}

Zamboni et al. (1997) found that although both visceral adipose tissue and glucose intolerance increased with age, differences in glucose tolerance disappeared after adjustment for visceral adipose tissue differences. Increased $\mathrm{W}: \mathrm{H}$, an anthropometric measure of abdominal fat deposition, is correlated with risk of atherosclerosis, thrombosis, and stroke (Walker et al. 1996). In the present study, on day 1 $\mathrm{W}: \mathrm{H}$ was positively correlated with fasting serum LDLcholesterol, serum insulin AUC and glucose AUC and negatively with plasma t-PA activity. Serum insulin AUC was correlated with plasma PAI-1 antigen level. Abdominal obesity is correlated negatively with t-PA antigen and positively with PAI-1 activity (Landin et al. 1990). The relationship of $\mathrm{W}: \mathrm{H}$ with the metabolic characteristics measured may be a consequence of the greater lipolytic activity of abdominal fat compared with gluteofemoral fat (Landin et al. 1990), which may, therefore, differentially influence postprandial serum NEFA concentration. Coon et al. (1992) found a correlation in healthy men between $\mathrm{W}: \mathrm{H}$ and the exponential rate of decline of plasma NEFA concentration during euglycaemic hyperinsulinaemic clamping; although no significant correlation $(P<0 \cdot 05)$ of AUC NEFA with the smaller range in $\mathrm{W}: \mathrm{H}$ was found in our data on day 1.

\section{Dietary fat content and serum non-esterified fatty acid concentration}

The morning serum TAG concentrations were similar for the isoenergetic $\mathrm{L}$ and $\mathrm{M}$ treatments, in agreement with the evidence (Whitley et al. 1997) that different inverse proportions of carbohydrate relative to fat in an isoenergetic meal lead to similar postprandial plasma TAG concentrations. Despite this similarity we found greater circulating serum levels of NEFA and glycerol throughout the day until 15.30 hours with treatment $\mathrm{M}$ than with treatment $\mathrm{L}$. These differences may have stemmed from differences in leakback (Frayn, 1993). Circulating TAG in treatment L is likely to have been predominately that of VLDL, and VLDL-TAG is known to be cleared more slowly than chylomicron TAG (Havel, 1994), which could have led to a slower NEFA release in treatment $\mathrm{L}$.

During starvation the NEFA: glycerol ratio of release from subcutaneous adipose tissue is close to 3:1 (Samra et al. 1996). At 13.30 hours with treatment $M$ the value was 6:1 and serum NEFA was elevated. This may indicate the combined influence, principally of HSL activity, but also a resistance to NEFA clearance, as the subsequent increase in serum insulin rapidly decreased serum levels of both NEFA and glycerol (Figs. 5 and 6). However, Frayn et al. (1997) reported that $80 \%$ of circulating NEFA 180300 min postprandially arose from the action of LPL in healthy subjects. On the other hand, their diets contained considerably more carbohydrate than did diet $\mathrm{M}$, and the inhibition of lipolysis by HSL can be blunted in insulinresistant states (Havel, 1972). In healthy subjects, plasma insulin concentrations exceeding 14-17 mU/l suppress HSL (Frayn et al. 1995). Serum insulin greatly exceeded this limit $1 \mathrm{~h}$ after breakfast with both treatments $\mathrm{L}$ and $\mathrm{M}$ (Frape et al. 1997b), when the treatment difference in serum NEFA was not significant, but by 3-4 $\mathrm{h}$ after breakfast the serum insulin level was below the limit with treatment $\mathrm{M}$ when the treatment difference in NEFA (Fig. 5) was greatest. It is possible, therefore, that treatment difference in serum NEFA concentration at 12.00 hours resulted to a considerable extent from treatment differences in HSL activity.

The fat source in both treatments was principally dairy, that has been shown to cause a larger NEFA response than that observed with olive oil when both were added to potato (Rasmussen et al. 1996), and the use by us of a dairy-fat source may have contributed to the large treatment difference. Moreover, Kiens \& Richter (1996) asserted that highglycaemic-index carbohydrates cause less insulin resistance than low-glycaemic-index carbohydrates, through lower 
serum NEFA levels. An increased circulating concentration of NEFA is known to suppress glucose oxidation (Ferrannini et al. 1983), and Pei et al. (1995) reported that plasma concentrations of both NEFA and glycerol were commensurate with the degree of resistance to insulin-mediated glucose disposal. Elevated circulating NEFA concentrations impair the action of key proteins in insulin binding and signal propagation in isolated hepatocytes by mechanisms related to their oxidation, and they reduce the number of hepatic binding sites for insulin (Svedberg et al. 1990, 1991). Moreover, an inability to adequately suppress postprandial plasma NEFA concentration is positively associated with elevated plasma PAI-1 activity in men (Toft et al. 1997). The results of the present experiment indicate that with fat of the composition employed, a relatively small amount at breakfast can lead to high circulating concentrations of NEFA that persists for $6 \mathrm{~h}$. These concentrations can then bring about a depression in glucose tolerance and an elevated insulin response, compared with the response to a carbohydrate breakfast.

\section{Acknowledgements}

The authors would like to express their thanks to Dr A. N. Howard for support and to Mrs Judy West and Mr Christopher Marshall for technical assistance and to the volunteer subjects who participated in the study. The authors are also very grateful to The Kellogg Company of Great Britain Ltd. for financial support.

\section{References}

Altman DG (1991) Practical Statistics for Medical Research. London: Chapman \& Hall.

Bjorntorp P (1990) 'Portal' adipose tissue as a generator of risk factors for cardiovascular disease and diabetes. Arteriosclerosis 10, 493-496.

Bligh EG \& Dyer WJ (1959) A rapid method of total lipid extraction and purification. Canadian Journal of Biochemistry and Physiology 37, 911-917.

Coon PJ, Rogus EM \& Goldberg AP (1992) Time course of plasma free fatty acid concentration in response to insulin: effect of obesity and physical fitness. Metabolism 41, 711-716.

Elwood PC, Renaud S, Sharp DS, Beswick AD, O'Brien JR \& Yarnell JWG (1991) Ischemic heart disease and platelet aggregation. The Caerphilly collaborative heart disease study. Circulation 83, 38-44.

Ferrannini E, Barrett EJ, Bevilacqua S \& DeFronzo RA (1983) Effect of fatty acids on glucose production and utilization in man. Journal of Clinical Investigation 72, 1737-1747.

Frape DL, Williams NR, Scriven AJ, Palmer C, O'Sullivan K \& Fletcher RJ (1997a) The effects of high- and low-fat meals on the diurnal response of plasma lipid metabolite concentrations in healthy middle-aged volunteers. British Journal of Nutrition 77, 375-390.

Frape DL, Williams NR, Scriven AJ, Palmer C, O'Sullivan K \& Fletcher RJ (1997b) Diurnal trends in responses of blood plasma concentrations of glucose, insulin, and C-peptide following high- and low-fat meals and their relation to fat metabolism in healthy middle-aged volunteers. British Journal of Nutrition 77, 523-535.

Frayn KN (1993) Insulin resistance and lipid metabolism. Current Opinion in Lipidology 4, 197-204.
Frayn KN, Coppack SW, Fielding BA \& Humphreys SM (1995) Coordinated regulation of hormone-sensitive lipase and lipoprotein lipase in human adipose tissue in vivo: implications for the control of fat storage and fat mobilization. Advances in Enzyme Regulation 35, 163-178.

Frayn KN, Summers LKM \& Fielding BA (1997) Regulation of plasma non-esterified fatty acid concentration in the postprandial state. Proceedings of the Nutrition Society 56, 713-721.

Friedewald WT, Levy RI \& Frederickson DS (1972) Estimation of the concentration of low-density lipoprotein cholesterol in plasma, without use of the preparative ultracentrifuge. Clinical Chemistry 18, 499-502.

Havel RJ (1972) Caloric homeostasis and disorders of fuel transport. New England Journal of Medicine 287, 1186-1192.

Havel RJ (1994) McCollum Award Lecture, 1993: triglyceriderich lipoproteins and atherosclerosis-new perspectives. American Journal of Clinical Nutrition 59, 795-799.

Holland B, Unwin ID \& Buss DH (1988) Cereals and Cereal Products. The Third Supplement to McCance and Widdowson's The Composition of Foods, 4th ed. Nottingham: Royal Society of Chemistry and Ministry of Agriculture, Fisheries and Food.

Holland B, Unwin ID \& Buss DH (1989) Milk Products and Eggs. The Fourth Supplement to McCance and Widdowson's The Composition of Foods, 4th ed. Cambridge: Royal Society of Chemistry and Ministry of Agriculture, Fisheries and Food.

Jeppesen J, Chen Y-DI, Zhou M-Y, Wang T \& Reaven GM (1995) Effect of variations in oral fat and carbohydrate load on postprandial lipemia. American Journal of Clinical Nutrition 62, 1201-1205.

Kiens B \& Richter EA (1996) Types of carbohydrate in an ordinary diet affect insulin action and muscle substrates in humans. American Journal of Clinical Nutrition 63, 47-53.

Landin K, Stigendal L, Ericksson E, Krotkiewski M, Risberg B, Tengborn L \& Smith U (1990) Abdominal obesity is associated with impaired fibrinolytic activity and elevated plasminogen activator inhibitor-1. Metabolism 39, 1044-1048.

Lopez-Segura F, Velasco F, Lopez-Miranda J, Castro P, LopezPedrera R, Blanco A, Jimenez-Pereperez J, Torres A, Trujillo J, Ordovas JM \& Pérez-Jiménez F (1996) Monounsaturated fatty acid-enriched diet decreases plasma plasminogen activator inhibitor Type 1. Arteriosclerosis and Thrombosis Vascular Biology 16, 82-88.

Lovegrove JA, Isherwood SG, Jackson KG, Williams CM \& Gould BJ (1996) Quantification of apolipoprotein B-48 in triacylglycerol-rich lipoproteins by a specific enzyme-linked immunosorbent assay. Biochimica et Biophysica Acta 1301, 221-229.

Lui GC, Coulston AM \& Reaven GM (1983) Effect of highcarbohydrate-low-fat diets on plasma glucose, insulin and lipid responses in hypertriglyceridemic humans. Metabolism 32, 750-753.

Ohlson LO, Bjuro T, Larsson B, Eriksson H, Svardsudd D, Welin L \& Wilhelmsen L (1989) A cross-sectional analysis of glucose tolerance and cardiovascular disease in 67-year-old men. Diabetic Medicine 6, 112-120.

Pei D, Chen YD, Hollenbeck CB, Bhargava R \& Reaven GM (1995) Relationship between insulin-mediated glucose disposal by muscle and adipose tissue lipolysis in healthy volunteers. Journal of Clinical Endocrinology and Metabolism 80, 33683372.

Paul AA \& Southgate DAT (1978) McCance and Widdowson's The Composition of Foods, 4th ed. London: HM Stationery Office.

Prins JB (1997) Food, obesity and non-insulin-dependent diabetes: are there molecular links? Proceedings of the Nutrition Society 56, 889-898.

Rasmussen O, Lauszus FF, Christiansen C, Thomsen C \& Hermansen K (1996) Differential effects of saturated and 
monounsaturated fat on blood glucose and insulin responses in subjects with non-insulin-dependent diabetes mellitus. American Journal of Clinical Nutrition 63, 249-253.

Samra JS, Clark ML, Humphreys SM, Macdonald IA \& Frayn KN (1996) Regulation of lipid metabolism in adipose tissue during early starvation. American Journal of Physiology 271, E541E546.

Statistical Package for Social Sciences (1993) SPSS for Windows version 6.0. Woking, Surrey: SPSS (UK) Ltd.

Svedberg J, Björntorp P, Lönnroth P \& Smith U (1991) Prevention of inhibitory effect of free fatty acids on insulin binding and action in isolated rat hepatocytes by Etomoxir. Diabetes $\mathbf{4 0}$, 783-786.

Svedberg J, Björntorp P, Smith U \& Lönnroth P (1990) Free-fatty acid inhibition of insulin binding, degradation, and action in isolated rat hepatocytes. Diabetes 39, 570-574.

Terpstra AHM (1985) Isolation of serum chylomicrons prior to density gradient ultracentrifugation of other serum lipoprotein classes. Analytical Biochemistry 150, 221-227.

Toft I, Bonaa KH, Ingebretsen OC, Nordoy A, Birkeland KI \& Jenssen T (1997) Gender differences in the relationships between plasma plasminogen activator inhibitor-1 activity and factors linked to the insulin resistance syndrome in essential hypertension. Arteriosclerosis and Thrombosis Vascular Biology 17, 553-559.

Walker SP, Rimm EB, Ascherio A, Kawachi I, Stampfer MJ \& Willett WC (1996) Body size and fat distribution as predictors of stroke among US men. American Journal of Epidemiology 144, 1143-1150.

Wenlock RW, Sivell LM \& Agater IB (1985) Dietary fibre fractions in cereal and cereal-containing products in Britain. Journal of the Science of Food and Agriculture 36, 113-121.

Whitley HA, Humphreys SM, Samra JS, Campbell IT, Maclaren DPM, Reilly T \& Frayn K (1997) Metabolic responses to isoenergetic meals containing different proportions of carbohydrate and fat. British Journal of Nutrition 78, 15-26.

Williams MJ, Hunter GR, Kekes-Szabo T, Snyder S \& Treuth MS (1997) Regional fat distribution in women and risk of cardiovascular disease. American Journal of Clinical Nutrition $\mathbf{6 5}$, $855-860$.

Zamboni M, Armellini F, Harris T, Turcato E, Micciolo R, Bergamo-Andreis IA \& Bosello O (1997) Effects of age on body fat distribution and cardiovascular risk factors in women. American Journal of Clinical Nutrition 66, 111-115. 


\section{Nuthition \\ Access full-text articles from the c $a b w e b$ British Journal of Nutrition on the Internet}

\section{http://nutrition.cabweb.org}

The British Journal of Nutrition is now available on the Internet through Nutrition CABWeb, our new service providing desktop access to information in nutritional science.

The service is open to all until the end of 1998. Access controls will be in place from January 1999, and members of institutions/organizations with a current print subscription will be able to access the electronic version of the $B J N$ for FREE once their institution/organization has registered.

Visit the site now to find out more about the service and for details on how to register.

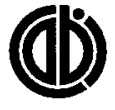

CABIP Publishing

CAB International

Wallingford

Oxon, OX10 8DE, UK

Tel: $+44(0) 1491832111$

Fax: +44 (0) 1491829198

Email: publishing@ cabi.org

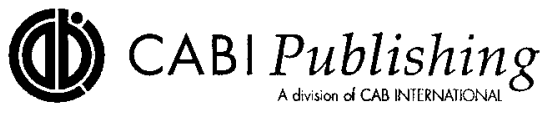

$\mathrm{CAB}$ International

10 East 40th Street, Suite 3203

New York, NY 10016, USA

Tel: +1 2124817018

Fax: +12126867993

Email: cabi-nao@ cabi.org 